\title{
Psycho-sociocultural Analysis of Attitude towards Littering in a Nigerian Urban City 1Ojedokun Oluyinka and ${ }^{2}$ Balogun, $\mathrm{S}$. K.
}

doi: $10.4314 /$ ejesm.v4i1.9

\begin{abstract}
This study examined the influence of altruism, environmental self-efficacy, locus of control, self-concept, age, gender, and level of education as predictors of attitude towards littering among residents of some selected communities in Ibadan metropolis. An ex-post cross-sectional research design was adopted for this study. Using a multi-stage sampling technique, one thousand, three hundred and sixty participants participated in the study. Their ages ranged from 18 to 65 years. Data collection was through a battery of measures combined into a single questionnaire. Pearson product-moment correlation, hierarchical multiple regression, and One-Way ANOVA statistical techniques were tools of testing hypotheses. Findings indicated that a combination of altruism, environmental self-efficacy, locus of control, self-concept, age, and gender explained 57\% of the variance in attitude towards littering. The relative contributions reveal that altruism (beta $=-.23, p<.01$ ), environmental selfefficacy (beta = -.18, $p<.01$ ); locus of control (beta $=.34, p<.01$ ), and self-concept (beta $=-.51, p<.01$ ) contribute significantly to attitude towards littering. Also, level of educational attainment has significant effect on attitude towards littering. These findings provide link between psychological factors and attitude towards littering, and suggest reasons for ineffectiveness of previous anti-littering campaigns among residents of Ibadan. Thus, the psychological variables in this study have implications for interventions on littering attitude.
\end{abstract}

Key words: Attitude, littering, psychosociocultural, urban city, Nigeria

\section{Introduction}

$\mathrm{L}$ ittering problem is an inherent fact of modern living that exists in one way or another in many countries, cities, and communities of the world. In Nigeria, urban litter is one of the most visible and persistent environmental issues facing the Oyo State Government, and costs the three tiers of government and community associations huge sum of money every year to clean up and repair the damage it causes. The urban city of Ibadan (the capital of Oyo State), a cosmopolitan town and the second most populous city in Africa, has its own share of a wide-spread litter problem that is associated with most urban towns; and is growing steadily with a well-felt negative impact on public health, quality of the environment, and sustainable growth of the city.

Over the years, Federal, State, local governments, together with community associations, have implemented a range of strategies to tackle the litter problem (Gazette No 8, Vol. 22 of $16^{\text {th }}$ May 1997; The Nation, 2007, October 5, pg. 38). In 2008, the Oyo State House of Assembly promulgated anti-littering laws aimed at prohibiting littering, monitoring, arresting, and fining of individuals who litter, especially in the State capital (Ibadan) and in the entire state. The government also established the Ministry of Environment and Water Resources in 2001, the introduction of Kerbsides Street sweeping in 1999, and the edict establishing the Ibadan Waste Management Authority (Gazette No 8, Vol. 22 of $16^{\text {th }}$ May 1997). Other strategies include anti-littering campaigns on both radio and television aim at changing people's behaviour when it comes to littering, and huge budgetary investment of about \#4.5 billion by both the Federal Government of Nigeria and Oyo State Government to evacuate solid waste from the nooks and crannies of Ibadan city by a private consortium from the United State (The Nation, 2007, October 5, pg. 38).

Unfortunately, these listed attempts have not met criteria for success (Bell \& Russell, 2002; The Nation, 2007), because Ibadan is dirty, and the problem of littering continues unabated (Ojedokun, 2009; Ojedokun \& Balogun, 2010). The failure of these attempts suggests it is an attitudinal problem, and indeed requires a psychological intervention. Legislation alone might not be enough in addressing attitudinal problem.

Geller, Winett, and Everett (1982), Stokols and Altman (1987), Keenan (1996) define littering as the careless, incorrect disposal of minor amounts of wastes. Littering is also leaving behind unwanted and unnatural elements in the environment (Green, 2001). Attitude towards littering is an individual's psychological tendency to evaluate or react with a certain degree of favour or disfavour towards throwing of wastes (e.g., packaging items, soft drink bottles (both plastic and metal), other bottles, glass, pure water nylons, fabric, chip and confectionary wrappers, metal cans, plastic straws, bottle caps, small pieces of papers, newspapers or magazines, vegetable waste

${ }^{1}$ Department of Pure and Applied Psychology, Adekunle Ajasin University, Akungba-Akoko, Ondo State, Nigeria .

yinkaoje2004@yahoo.com ${ }^{2}$ Department of Psychology,University of Ibadan, Ibadan, Nigeria 
and food scraps, household wastes, cigarette butts, milk tins, sweet or crisp wrapper, piece of chewing gum, etc) on bare ground. Attitude is cognitive, affective, and normative in character.

According to Kaiser, Wolfing, and Fuhrer (1999), negative attitude to littering is necessary for voluntary participation in pro-environmental actions. If this attitude is actually translated into behaviour, then there might be significant reductions in time spent on sanitation and cleaning activities, and in money and manpower costs associated with serious health and environmental problems. Resources freed from these activities could be channeled toward other projects that would enhance the well-being and quality of life of the populace. Beyond the quality of life concern, negative attitude towards littering might be correlated with decrease in family and community health hazards, bad odour, proliferation of flies, cockroaches, rats, and other small and dangerous insects which breed ailments on dirties that may endanger human health. Clearly, negative reactions toward littering could be an indicator of "culture" of cleanliness and community shared responsibility.

Despite the benefits associated with negative attitude towards littering, the high level of environmental concern all over the world, and existence of anti-littering laws and environmental taboos in Nigeria, very few residents of Ibadan seem to have aversion for littering. This might be because littering is an automatic and routine behaviour; people repeat it because this behaviour is easy, comfortable, or rewarding. However, people might differ on their attitude towards littering.

Reasonably, the question arises: why would some residents have negative attitude towards littering while others do not? Intuitively, the answer could be that those who have negative towards littering possessed some characteristics that regulate their thinking, felling, and action when it comes to littering. Pleasant as this intuition sounds, an empirical investigation of it is rare in Nigeria, especially in the area of psychosociocultural predictors of attitude related to littering.

\section{Predictors of Attitude related to Littering}

Psychosocicultural predictors of attitude toward littering are poorly understood and findings of existing studies conflict and appear inconclusive. Broadly speaking, a number of approaches to predict behaviour in the peerreviewed literature are based on the assumption that behaviour is either a product of the individuals' psychological processes or the sociocultural context. One set of approaches studies and models behaviour mainly as a function of personality characteristics which are conceived as stable and relatively permanent, thus behaviour and attitude will be consistent from one situation to another. A second set studies behaviour and attitude as largely been determined by situational factors external to the individual (e.g., sociocultural/economical, urban planning, architectural, institutional and legal policies, and social practices), thus will vary considerably across situations. The first ('internal') perspective carries an implicit assumption of individuals as atomistic agents autonomous of social structure, while the second ('external') perspective sees individual been heavily influenced by external forces beyond their comprehension or control.

Although cumulative evidence is contradictory and inconclusive, literature in the area of environmental related attitude is typical of internal-external divergence in perspectives. Internalist approaches focus exclusively on personality factors as predictors of environmental related attitude. For example, Hines, Hungerford, \& Tomera (1986-1987) found in a metal-analysis that locus of control is associated with environmental related behaviour; findings of Clark, Clemes, and Bean (2000), Clemes and Bean, (1996) suggest that self-concept influences individuals' feeling, thinking, learning, action, value, and relationship with others, including the environment. Milfont (2007) reported that individuals with pro-environmental attitude are altruistic. Externalist perspectives such as AlKhatib, Arafat, Daoud, and Shwahneh (2009) and Arafat, Daoud, and Shwahneh (2007), report that socio-cultural factors such as gender, marital status, monthly income, religious convictions constraints, education level, age, and type of residence promote littering. A number of studies (e.g., Banerjee \& McKeage, 1994; Mohai, 1992; Zelezny, Chua, \& Aldrich, 2000) have found that females are more concerned with environmental related issues than males. Samdahl and Robertson (1989) reported no correlation between gender and environmental related attitude. Curnow, Streker, and Williams (1997) also reviewed the literature on the influence of socio-cultural factors. They found some literature indicating that males are more likely to litter than females, but they found more literature that found no gender difference or that was inconclusive. Scott (1999), Hallin (1995) found that age correlates positively with environmental behaviour. However, Place 
and Eweret (2001) and Teisl and O'Brien (2003) reported that younger people are more environmentally concern than older people. Curnow et al. also identified studies that found older people to litter more than younger people, but also studies that found the opposite or that found no difference at all. Also, individuals with more education in general are more concerned about the environmental related issues (Chanda, 1999). However, a study in Norway, Grendstad and Wollebaek (1998) found the opposite. This inconsistency might be due to different settings of the studies.

A problem with the past studies is that they have narrowly studied range of predictors from singular approaches than from combining both psychological and socio-cultural factors in a single study. By using a singular approach, researchers and practitioners might be prevented from seen the complex nature of attitude towards littering through a psychosociocultural lens, this may be hazardous. Thus, a unified theory expected to provide multidimensional explanations and interventions for tackling littering problem should be wide spectrum in approach.

\section{The Present Study}

The theoretical framework for the present study rests on the assumptions of both interactionism and organismic/dialectical theories, and it overcomes the internal-external dichotomy controversy. Interactionism and organismic theories advance over older deterministic theories that attributed most or all of the causes of human behaviour and attitude either to the person (i.e., psychological processes) or to the situation (e.g., socio-cultural factors). In interactionism, person and situation are separate entities, but they are continually engaging in a series of interactions. Organismic theory emphasizes the dynamic interplay of socio-cultural, societal institutions, and individual factors in a mutual, complex system (Van Liere \& Dunlap, 1981). From the perspectives of both Interactionism and organismic theory, attitude toward littering for an example may be studied from both socio-cultural constraints and individual motivation or psychological processes perspectives. This holistic view of psychosociocultural angle to proenvironmental attitude has been presented by Hines et al. (1986-1987), but has not been extensively investigated. Hence in this study, a combination of psychosociocultural factors is expected to influence attitude towards littering.
Given the limitations of previous studies and the fact that in developed countries, many studies have been conducted to evaluate and apply strategies to reduce pollution by behavioural control of littering, surprisingly, in developing countries, literature on littering attitude, its predictors, and strategies to reduce it are scanty; yet many urban centers in developing countries, including Ibadan (the capital of Oyo State, Nigeria), suffer from a widespread littering problem. Then the primary purpose of this study is to fill a gap in the literature by examining how psychosociocultural factors (altruism, environmental self-efficacy, locus of control, selfconcept, age, gender, and level of education) might influence attitude towards littering. The goal is to study a sufficiently large sample to explore the combine influence of psychosociocultural variables in an effort to profiling the predictors of attitude towards littering.

The psychological variables are chosen because they are self-initiated psychological processes that could regulate habitual attitude. Socio-cultural factors are chosen because they are considered a product of increasing pressures on individuals to conform to stereotypical role definitions promoted by socio-cultural agents. Ajzen and Madden (1986) refer to these factors as constraints and facilities on behaviour beyond people's control. Inclusions of such factors are seen as particularly important in the ecological domain (Hines et al. 1986-87; Granzin \& Olsen, 1991; Guagnano, Stern, \& Dietz, 1995). For instance, in some traditional African settings, the cleaning of the compound is belief to be an uncontested duty of the women and the children, and the slave where applicable. Such beliefs might not be conducive for positive waste management practices in the modern Nigerian setting as exemplify in most developed nations. However, it is possible that everybody is not influenced by socio-cultural pressures and that they have the ability to resist external pressures, and act more in accordance with their own selfcongruent values. This is a task for empirical investigation.

This study has both theoretical and practical values. If found that a combination of psychosociocultural factors significantly predict attitude towards littering, this knowledge will highlight the importance of using both interactionism and organismic theories in providing holistic explanation for testing a combination of attitude predictors than say a 
single perspective. Practically, findings will provide benchmark measures for interventions to various stakeholders such as environmental psychologists, health psychologists, organisational/industrial psychologists, policy formulators, Ministry of environment and water resources, waste management authority, urban and regional planners, health officers/sanitary inspectors, community groups, packaging and fast food companies, non-government organisations, community opinion leaders, and researchers alike by showing how a combination of psychosociocultural factors can influence attitude toward littering. Lessons learnt from this can be used to provide a model for designing and implementing litter interventions/campaigns that can be used at any scale and that can be adapted for use in education campaigns in other areas and settings.

\section{Relationship between Psychological Factors} and Attitude related to Littering

Altruism is an individual disposition that reflects a tendency to behave in a way that improves the well-being of another person or nonhuman species (Batson, 1987). Altruism tendency has the potential for regulating littering behaviour in a traditional Nigerian society. In the traditional Nigerian society, and indeed the African society, pro-social attitude is a cultural trait shared (not to be taken as absolute uniformity), part of the communal living injunctions is that you have to be your neighbour and brother's keeper. This is implies that whatever is done to others including the environment, either "good or bad", has direct or indirect consequences. For the perpetrator/s, immediate family members, friends, or acquaintances, extended family members, and investments. As a result, compounds and building surroundings are communally kept clean in the traditional Nigerian society. This becomes a cultural norm because of its influence on the unity and solidarity of the community. Theoretically, when individuals grew up in such an environment dominated with altruistic actions, and they have internalised the cultural norm related to environmental cleanliness, such individuals are expected to exhibit higher level of proenvironmental attitude. For individuals doing so, it brings intrinsic satisfaction and commitment to societal goals. Then, altruistic individuals are expected to report negative attitude towards littering because of their selfless disposition to consider the consequences of littering on the welfare of others.
According to Wood, Bandura and Bailey (1990), perceived self-efficacy is an individual's belief or confidence in his/her abilities to perform and succeed in challenging situations through applying his/her own motivation, cognitive resources, and specific actions. This study operationalises environmental self-efficacy as confidence of an individual in his or her ability to successfully performing behaviours that can solve environmental problems in the face of different barriers. Environmental self-efficacy construct has both theoretical and practical implications for attitude towards littering because taking adaptive environmental action in the face of constraints requires the belief that one has the knowledge, skills, and abilities necessary to perform successfully. For high environmental selfefficacious, previous successful experience with littering problem might prepare the individual to evaluate littering negatively. Luszcynska, Gutiérrez-Doña, and Schwarzer (2005) posited that self-efficacy influences the success of the futuristic self-producing resiliency through reinforcement of past successes.

Locus of control (Rotter, 1966) refers to an individual's perception about the underlying causes of events in life. Internalisers judge outcomes of events to be internally controllable. That is, they believe that their own personal efforts, behaviours, competence, ability, or skills will influence and determine outcomes, and they take responsibility for their actions. Internalisers are likely to belief that personal actions are needed to reduce littering, rather than dependence on actions by authorities. Externalisers attribute events to external sources. They believe and behave as if forces beyond their control such as chance, luck, fate, or powerful others represent the important factors in determining the occurrence of reinforcing events. As such, their own effort or abilities are perceived to have little effect on outcomes. Externalisers are more likely to hold someone else (e.g., those who are supposed to tidy up the streets and those who are supposed to provide litter bins, or empty them) responsible for their littering habit. Locus of control might be an explanation for why two individuals might vary on attitude towards littering.

According to Tuttel and Tuttel (2004), self-concept is a set of attitudes and values or personal attributes, qualities, abilities, and actions that individual hold about self. People who feel positively about themselves are more likely to pursue and achieve desirable outcomes in their 
performance than individuals who do not feel positively about themselves. Participants with high self-concept are likely to disconfirm attitude that does not maintain correspondence with their self-evaluation, hence they are more likely to report negative attitude towards littering. Selfconcept based theory suggests that how a person views self-influences his or her behaviour including thinking, feeling, and acting (Shamir, House, \& Arthur, 1993).

Based on the interactionism and organismic theories and previous findings, a combination of psychosociocultural factors is anticipated to independently and jointly influence attitude towards littering. It is hypothesized that-

1. Altruism, environmental self-efficacy, locus of control, and self-concept will independently influence attitude towards littering, and this influence would hold after controlling for gender and age.

2. Altruism, environmental self-efficacy, locus of control, self-concept, gender, and age will jointly influence attitude towards littering.

3. Level of education would significantly influence attitude towards littering.

\section{Study Area}

Ibadan, the capital city of Oyo State is an urban city located in the humid Southwest of Nigeria. It is on a major transport route to the northern parts of Nigeria, and is the largest of contemporary traditional Yoruba towns. Ibadan is composed of the main city and its suburbs. Administratively, Ibadan metropolis was under one local government; the Ibadan Municipal Government, before it was split into five distinct local government areas (LGA) in 1991. The five LGAs are Northeast, North Central, Northwest Southeast, and Southwest. The 1,338,659 inhabitants of the main city according to census results of 2006 represent 24.34 percent of Oyo State. In this study, data collection was among residents of Ibadan North-east and South-east local government areas. These areas are considered as core and transitory areas of Ibadan (Onibokun, 1973). Justifications for selecting them include, residents of these areas are from a wide spectrum of social and economic status, the areas comprise of both inner core (indigenous or high density communities) and transitory communities (developed with little or no space for further development). Their choice ensures that the environment is identical for all the participants.

\section{Methodology}

This section discusses the design of the survey research study, including the instrument of data collection, the participants and sampling methods used to select them, and the statistical techniques used to analyse the data collected.

\section{Sample and sampling procedure}

This is a descriptive correlational study with a cross-sectional design in which all the variables are assessed at the same time (Hernandez, Fernandez, \& Bapitsta, 2003). None of the variables of study are directly manipulated, and some correlation is likely to exist between any pair of the independent variables. The independent variables are altruism, environmental self-efficacy, locus of control, self-concept, gender, age, and level of education. The dependent variable is attitude towards littering. Inclusion criteria for participating in the study were adult age (18years and above), met at the study setting, and physically and cognitively able to respond to a survey. One thousand, three hundred and sixty $(n=1360)$ individuals participated in the study. Their ages ranged from 18 to 65 years (Mean= 32.36, $\mathrm{SD}=10.98$ ). A multistage sampling technique was used in the selection of the participants. Firstly, two local government areas were purposive selected for data collection. Secondly, cores and transitory areas were identified according to the recommendation of Mabogunje (1963). Using the Nigerian National Population Commission's list of communities, thirty two $(n=32)$ communities within Ibadan North-East, and another twenty nine $(n=29)$ communities within Ibadan SouthEast were identified. After the identification of these communities, simple random technique (odd and even) was used to select at least fifty percent (50\%) of the communities from each local government area. A proportional technique was used to allot questionnaires to the selected communities. Lastly, two thousand $(2,000)$ questionnaires were randomly administered to consented adults. After questionnaires administration which lasted for a period of 4 months, a total of one thousand, five hundred and twenty $(n=1,520)$ questionnaires were retrieved. The collected questionnaires were screened for adequacy and missing data, after which one thousand three hundred and sixty completed questionnaires were selected for data analysis. The rest were rejected due to missing information. Data collection was under the condition of anonymity, and consent for the management of the data found in the research was considered implicit in willingly agreeing to complete the 
questionnaire for the survey. For these reasons, no written consent for participation was obtained. The purpose of the study was explained to each participant before administration of the instrument, and only those who willingly consented to participate in the study were given questionnaires to complete. No incentive is giving.

Descriptive method was used to categorise the data. To explore the extent to which variables of the study are interrelated, Pearson productmoment correlation was conducted. Hierarchical multiple regression analysis was performed in order to control for the influence of gender and age on attitude towards littering, and to assess whether or not the explanatory variables have significant influence on the criterion variable. The tool was also used to test for the joint and independent influence of psychosociocultural factors on attitude towards littering. One-way ANOVA was used to test for the effect of level of education on attitude towards littering. The results of various analyses are presented under the results and discussion subsections.

\section{Descriptions of measures}

The participants were assessed by means of a self-reported questionnaire that consist five instruments (i.e., altruism, environmental selfefficacy, locus of control, self-concept, and attitude towards littering) with items arranged in a mixed order.

Socio-demographic variables: The biographical data information sheet was used to tap demographic information of participants such as gender, age, marital status, and level of education.

The Interpersonal Reactivity Index (David, 1996). This scale consists of 7-item that tap the altruism tendency of an individual on a 5-point Likert type scale ranging between 5 (strongly agree) and 1(strongly disagree). Scores above the mean value indicate high altruism tendency, and scores below the mean value indicate selfcenteredness or low altruism tendency. Items include "When I see someone being cheated, I feel kind of protective toward them" and "I would describe myself as a pretty soft-hearted person". David (1996) reports a co-efficient alpha of 0.79 for the scale. An alpha co-efficient of 0.59 , and Unequal length Spearman-Brown split half reliability of 0.56 were obtained in this study.

The English version of German version of environmental self-efficacy scale (Harkness, Scholz, \& Stadler, 2002) was administered as a measure of environmental self-efficacy. This scale contains 5-item with response on a 5-point Likert format of 5(strongly agree) and 1(strongly disagree), so that scores above the mean value reflect high environmental self-efficacy, and scores below the mean score indicate low environmental self-efficacy. Items include "It is just too difficulty for someone like me to do much about the environment" and "There is no point in doing what I can for the environment unless others do the same". This measure has demonstrated high reliability of 0.86 in adult studies (Harkness et al. 2002). In this study, an alpha co-efficient of 0.84 , and split half reliability of 0.81 were obtained.

The locus of control scale (Craig, Franklin, $\&$ Andrew, 1984) was used to measure locus of control. The scale consists of the 17 items rated on a 5-point Likert type scale between 5 (strongly agree) and 1(strongly disagree), so that scores above the mean value indicate external orientation, and scores below the mean value indicate internal orientation. The following item had reversed scores: 2,3,4,6,9,10,11,12,14, and 17. Items include "I can anticipate difficulties and take action to avoid them" and "I can control my problem(s) only if I have external support". Internal consistency of the scale ranges from 0.79 to 0.75 (Craig, et al. 1984; Taiwo, Olapegba, \& Adejuwon, 2005). In this study, an alpha coefficient of 0.78 , and split half reliability of 0.78 were obtained for the scale.

The bipolar adjective pairs (Devins, Beanlands, Mandin, \& Paul (1997) was used to measure self-concept. The scale represents three dimensions of meaning (evaluation, potency, and activity) according to Osgood, Suci, and Tannenbaum (1957). The scale consists of 13item rated on a 7-point Semantic-differential technique (Osgood et al. 1957). However, for easy understanding and comprehension by participants; and to be consistent with response pattern of other scales, the rating pattern was changed to 5-point scale of "strongly agree $=5$ to strongly disagree $=1$ ", so that scores above the mean value mean high self-concept, and score below the mean value indicate low self-concept. Items include "I am good", I am wise", "I am friendly", and "I am egoistic". In this study, an alpha co-efficient of 0.80 , and split half reliability of 0.81 were obtained for the scale.

The attitude towards littering scale (Ojedokun, 2009) was used to measure the individuals' psychological tendency to react to littering. The scale is a 24 item self-reported questionnaire based on the three components of 
attitude cognition, affection, and connative. The scale is rated on a 5-point Likert scale ranging from "strongly agree $=5$ " to "strongly disagree $=1$ ", so that higher scores above the mean value represent positive attitude, and low scores below the mean value indicate negative attitude. Items include "I feel uncomfortable when seeing litter on bare ground", "Seeing someone litter upset me", "Litter is not a problem in my community", and "I try to keep litter in wastes bin", "I never like litter". The scale demonstrated good internal consistency at the pilot stage and in the present study with an alpha coefficient that ranges from 0.75 to 0.86 , and split half reliability of 0.65 to 0.92 . Evidence for the construct validity of the scale is presented elsewhere (see Ojedokun, 2009).

\section{Results and Discussion}

Table 1 reveals demographics information of the participants, where there are males (56.6\%) and females $43.4 \%$. Marital status varied from single $49.1 \%$, married $44.0 \%$, divorced $2.4 \%$, separated $2.3 \%$, and widowed $2.2 \%$. About $16.5 \%$ of respondents had primary school certificate, $38.5 \%$ had secondary school certificate, $16.4 \%$ had teacher training certificate, $19.7 \%$ were diploma holders or its equivalent, $6.5 \%$ had bachelor degrees or its equivalent, and $2.5 \%$ had masters. $24.5 \%$ of the respondents were government employees, $4.9 \%$ were in private organizations, artisans $9.0 \%$, traders $25.2 \%$, selfemployed $6.3 \%$, Clergies $0.4 \%$, retirees $0.8 \%$, students $26.3 \%$, and unemployed $2.7 \%$. About $42.4 \%$ participants were from fifteen communities in Ibadan South-East and 57.6\% participants were from sixteen communities in Ibadan North-East. Lastly, there are tenants (49.4\%), landlords (18.4\%), and living with others (32.2\%). These findings show that participants in this study cut across different socio-economic status, thus their responses might reflect opinions of most people about the matter in question. This implies that public perception and attitude studies related to littering are very important for establishing management and strategic priorities.

This study had three goals. The first goal was to analyze the relationship between psychosocio-cultural factors and attitude towards littering. Results of the correlational analysis are presented in Table 2. Majority of the variables are found to have significant low, moderate, and high correlations. Altruism ( $\mathrm{r}=-.23, p<.01)$, and environmental self-efficacy $(\mathrm{r}=-.21, p<.01)$ correlate negatively but weakly with attitude towards littering, suggesting that when scores on altruism and environmental self-efficacy increase, attitude towards littering is more likely to be negative. However, negative strong correlation exists between self-concept and attitude towards littering $(r=-.69, p<.01)$, implying that when scores on self-concept increase, attitude towards littering is likely to be negative. Also, positive and strong correlation exists between locus of control $(r=.50, p<.01)$ and attitude towards littering, this means that when individuals tend towards internal orientation, attitude towards littering is likely to be negative. Therefore, altruism, environmental self-efficacy, locus of control, self-concept, and attitude towards littering are significantly related. Results also show significant negative but weak relationship between age $(r=-.13 ; p<.05)$ and attitude towards littering, suggesting that as individuals grow older, attitude towards littering becomes negative. There is no significant relationship between gender $(r=-.03 ; \mathrm{p}>.05)$ and attitude towards littering, suggesting that other variables beyond gender influence attitude towards littering. These findings are congruent with previous studies that report relations between some psychosociocultural factors and environmental related attitudes (see Hines et al. 1986-1987; Clark et al. 2000; Clemes \& Bean, 1996; Milfont, 2007; Al-Khatib et al. 2009; Arafat et al. 2007; Banerjee \& McKeage, 1994; Zelezny et al. 2000), but are contrary to some previous (see Samdahl \& Robertson, 1989; Place \& Eweret, 2001; Teisl \& O'Brien, 2003).

Our second aim in this study was to investigate the extent to which the psychological factors significantly predict attitude towards littering, after controlling for age and gender. Hierarchical multiple regression was conducted using altruism, environmental self-efficacy, selfconcept, and locus of control as predictors to explain variance in attitude towards littering above and beyond that of age and gender. The results are presented in Table 3. On the first step, the control variables (i.e., age and gender) were entered. As a set, they accounted for zero percent of the variance in attitude towards littering $\left(R^{2}=\right.$ $.00, p>.05)$. With regard to specific variable, gender (beta $=-.01, p>.05$ ) and age (beta $=-.03, p$ $>.05)$, each had no significant influence on attitude towards littering. These findings are contrary to previous results in these areas (see AlKhatib et al. 2009; Arafat et al. 2007; Banerjee \& McKeage, 1994; Mohai, 1992; Zelezny et al. 2000; Hallin, 1995; Place \& Eweret, 2001; Teisl \& O'Brien, 2003). However, Samdahl and 
Robertson (1989) reported no correlation between gender and environmental related attitude which is consistent with the finding in this present study. The lack of significant influence of both age and gender on attitude towards littering places considerable doubt on the commonly held belief that the stereotypical role definition regarding the cleaning of the environment in some traditional Nigerian settings is responsible for low environmental concern among men and older people. It is therefore important to consider other explanations for the discrepant findings. One possible explanation for the contradictory findings is that in the traditional Ibadan city women and children are mostly home keepers while men and older members of the family go out to look for "food". But, the city has grown bigger and its commercial activities have become welldeveloped where adult, children, women, and men alike are at the forefront. Thus, there is a tendency towards individuation, low sense of belongingness, and shortage of infrastructures which could be responsible for detestable environmental condition in the city now.

On the second step the psychological variables (altruism, self-concept, locus of control, and environmental self-efficacy) were entered. As hypothesised and in line with previous studies (Hines et al. 1986-1987; Clark et al. 2000; Clemes \& Bean, 1996; Milfont, 2007), these variables accounted for $57 \%$ of the variance in attitude towards littering $\left(R^{2}=.57, p<.01\right)$ after controlling for the influence of age and gender. This finding confirms hypothesis one that altruism, environmental self-efficacy, selfconcept, and locus of control will independently influence attitude towards littering, and this influence will hold after controlling for age and gender. Consistent with the hypothesis, altruism (beta $=-.23, p<.01$ ), environmental self-efficacy (beta $=-.18, p<.01$ ), locus of control (beta $=.34$, $p<.01$ ), and self-concept (beta $=-.51, p<.01$ ) respectively display significant influence on attitude towards littering. The magnitude of the contribution of each of the independent variables is given by the part correlation $\left(\mathrm{sri}^{2}\right)$. For altruism $\left(\mathrm{sri}^{2}=-.11\right)$, environmental self-efficacy $\left(\mathrm{sri}^{2}=\right.$ $.16)$, locus of control $\left(\mathrm{sri}^{2}=.29\right)$, and self-concept $\left(\mathrm{sri}^{2}=-.45\right)$.

On the third step both psychological and socio-cultural variables (altruism, environmental self-efficacy, locus of control, self-concept, age, and gender) were entered. As a set, these variables accounted for $57 \%$ of the variance in attitude towards littering $\left(R^{2}=.57, p<.01\right)$. The second hypothesis was that altruism, self-concept, locus of control, environmental self-efficacy, age, and gender will jointly influence attitude towards littering. The results indicate that the six predictor variables jointly predicted attitude towards littering $\left(R^{2}=.57, p<.01\right)$. Hence, hypothesis two was confirmed. These results dovetail with the positions of interactionism and organismic theories that a combination of psychological and socio-cultural factors is likely to influence behaviour and attitude.

The third goal was to investigate the effect of educational attainment on attitude towards littering. Consistent with prior finding (see Chanda, 1999), results show a significant effect of educational attainment on attitude towards littering, $F(5,1353)=2.26, p<.05$. Post-hoc (LSD) test reveals the differences on attitude towards littering based on different levels of education. Participants with teacher training education $(\bar{X}=79.11$, SD $=11.86)$, and those with school certificate education $(\bar{X}=79.50$, SD $=12.96)$ are more negative towards littering compared to those with primary school education $(\bar{X}=77.20, \mathrm{SD}=12.93)$. Results also indicated that participants with polytechnic/college of education certificate $(\bar{X}=82.00, \mathrm{SD}=16.73)$ are more negative towards littering compared to those with teacher training certificate $(\bar{X}=79.11, \mathrm{SD}=$ 11.86). Mean ratings of other groups were not significantly different from one another. It is possible to attribute some of these findings to exposure to environmental related issues during attendance at a college or university; and higher social maturity attributed to moderate educational attainment. At least, individuals with some level of education are expected to cultivate and exhibit good social etiquettes, these should contribute to their negative attitude towards littering. Thus, hypothesis three was accepted.

\section{Conclusion}

In conclusion, this study found support for the hypothesis that a combination of psychosociocultural factors would influence attitude towards littering. However, this support must be regarded as weak considering the lack of significant contributions from age and gender to the joint prediction of attitude towards littering. The support for significant effect of level of education was even weaker. We believe that the socio-cultural variables adopted for this study, relating to attitude towards littering as well as the psychological factors are reasonable choices as 
are the hypotheses. Still, one cannot conclude from the present study that participants' sociocultural characteristics are unimportant in explaining attitude towards littering. There could be other socio-cultural factors, not considered in this study, that predict individual evaluation of littering. It is our strong intuition that littering problem is a multidimensional behavioural issue, and therefore requires a psychosociocultural approach.

The findings of the present investigation established that psychological factors predicted attitude towards littering better than socio-cultural characteristics, and have significant implications for the usefulness of altruism, environmental selfefficacy, locus of control, and self-concept as potential means of facilitating anti-littering attitude. Because the direction of relationship is that individuals who score low on altruism tendency, low on environmental self-efficacy, low on self-concept, and externally oriented individuals are more likely to report positive attitude towards littering, therefore psychologists and other experts in behavioural science who have the professional knowledge should foster their effort on designing interventions that would accentuated the psychological resources that are relevant for anti-littering attitude for those individuals who are low on specific psychological resources. These programmes should be valuable to various stakeholders who have litter reduction as their focus. Although pursuit of these interventions is clearly beyond the scope of the present study, this is an important area for future research.

Findings also reveal no significant influence of gender and age on attitude towards littering. Of particular note is the lack of significant relationship between age and attitude towards littering despite the significant negative relationship suggests by bivariate analysis.

\section{References}

Ajzen, I., \& Madden, T. J. (1986). Prediction of goal-directed behaviour: Attitudes, intentions, and perceived behavioural control. Journal of Experimental Social Psychology, 22, pp453-474. Al-Khatib, I. A., Arafat, H. A., Daoud, R., \& Shwahneh, H. (2009). Enhanced solid waste management by understanding the effects of gender, income, marital status, and religious convictions on attitudes and practices related to street littering in Nablus - Palestinian Territory. Waste Management, 29, pp 449-455.

Arafat, H., Al-Khatib, I., Daoud, R., \& Shwahneh,
However, observations of both bivariate and hierarchical regression analyses suggest that the significant correlation obtained might be due to the impact of other variables in the bivariate analysis unlike in regression analysis where the influence of other variables are controlled. Hence, multiple messages will be more effective in addressing littering phenomenon among participants in this study, as well as in other settings. Public awareness at all levels, with emphasis on males, females, young, old, and residents with low educational status, as the primary target groups, should be a way of bringing about litter reduction in Ibadan. Lastly, as observed during data collection, people may be forced to litter due to shortage of litter disposal facilities, especially in a cosmopolitan and urban city like Ibadan. Therefore, as a technical solution, the Oyo state government, the local government authorities, waste management authorities, private and public organisations, and communities and landlord association should provide more litter bins and ensure removal of litter after occurrence.

As limitations of the study, the nonexperimental nature of the study contributes little to cause-effect relationship among the variables. Future researchers could conduct experimental studies in order to make stronger inferences regarding causality, and to find out whether the attitude actually translates into behaviour. Due to the sensitive nature of the issue under consideration, the participants might have responded to the statements in a social desirable way to makes them look "good". Thus social desirability effect is possible in the results of this study. Future research could investigate the impact of social desirability by adding measures of self-presentation (e.g., self-monitoring) to other self report measures.

H. (2007). Influence of socio-economic factors on street litter generation in the Middle East: Effects of education level, age, and type of residence. Waste Management \& Research 25 (4), pp363-370.

Banerjee, B., \& McKeage, K. (1994). How green is my value: Exploring the relationship between environmentalism and materialism, In Allen C. T. and John, D. R. (Eds.) Advances in consumer research, association for consumer research, Provo, UT, Vol. 21, pp. 147 - 52. 
Batson, C. D. (1987). Prosocial motivation: Is it ever truly altruistic? Advances in Experimental Social Psychology, 20, pp65-122.

Bell, R. G., \& Russell, C (2002). Environmental policy for developing countries. Issues in Science and Technology, Spring 2002.

Chanda, R. (1999). Correlates and dimensions of environmental quality concern among residents of an African subtropical city: Gaborone, Botswana. Journal of Environmental Education, 30(2),pp 3139.

Clark, A, Clemes, H, \& Bean, R. (2000). Como desarrollar la autoestima en adoelscentes (How to develop self-esteem in adolescents), Madrid: Editorial Debate.

Clemes, H, \& Bean, R. (1996). Como desarrollar la autoestima en los ninos. (How to develop selfesteem in children), Madrid: Editorial Debate. Craig, A. R, Franklin, J. A, \& Andrew, G. (1984). To measure locus of control of behaviour. British Journal of Medicine, 57,pp 173-180.

Curnow, R; Streker, P; \& Williams, E. (1997).; Understanding littering behaviour in ;Australia: $A$ review of the literature. Beverage Industry Environment Council, Pyrmont, Australia David, M. H. (1996). Interpersonal reactivity index in empathy: A social psychology approach. Boulder, Co: Westview Press.

Devins, G. M, Beanlands, H, Mandin, H, \& Paul, L.C. (1997). Psychosocial impact of illness intrusiveness moderated by self concept and age in end-stage renal disease, Health Psychology, 16 (6), pp529-538.

Federal Republic of Nigeria Official Gazette (15 May 2007). Legal notice on publication of the details of the breakdown of the national and state provisional totals 2006 Census.

http://www.nigerianstat.gov.ng/nbsapps/onnection s/Pop2006.pdf. Retrieved 08/10/2010.

Geller, E. S., Winett, R. A., \& Everett, P. B. (1982). Preserving the environment: Strategies for behaviour change. Elmsford, NY: Pergamon Press.

Granzin, K. L. \& Olsen, J. E. (1991).

Characterizing participants in activities protecting the environment: A focus on donating, recycling, and conservation behaviours. Journal of Public Policy \& Marketing 10, pp1-27. Grendstad, G, \& Wollebaek, D. (1998). Greener still? An empirical examination of Eckersley's ecocentric approach. Environment \& Behaviour, 30(5), pp653-675.
Green, C.A. (2001). The effect of prior litter on sewing class students`clean-up behaviour. http://www.clearinghouse.missouriwestern.edu/de fault.asp. Curled from the Internet on $14^{\text {th }}$ Dec, 2007.

Guagnano, G. A., Stern, P. C., \& Dietz, T. (1995). Influences on attitude-behaviour relationships: A natural experiment with curbside recycling. Hallin, P. O. (1995). Environmental concern and environmental behaviour in Foley, A small-town in Minnesota. Environment and Behaviour, 27, pp 558-578.

Harkness, J, Scholz, E, \& Stadler, S. (2002). ISSP Germany 2000 environment II: ZUMA report on the Germany study. London: National Center for Social Research.

Hernandez, R., Fernandez, C. Y., \& Bapitsta, P. (2003). Metodología de la Investigación $\left(3^{\text {rd }}\right.$ ed). [Methodology of Research]. México: McGraw Hill, $705 \mathrm{p}$.

Hines, J. M, Hungerford, H. R, \& Tomera, A. N. (1987). Analysis and synthesis of research on environmental behaviour. A meta-analysis. Journal of Environment Education, 18, pp 1-8. Kaiser, F.G., Wolfing, S., \& Fuhrer, U. (1999). Environmental attitude and ecological behaviour, Journal of Environmental Psychology19 ppl-19. Keenan, M. (1996). The A, B, C of litter control. Irish Journal of Psychology, 17 (4), pp327-339. Luszcynska, A, Gutiérrez-Doña, B, \& Schwarzer, R. (2005). General self-efficacy in various domains of human functioning: Evidence from five countries. International Journal of Psychology, 40(2) pp 80-89.

Mabogunje, A. I. (1963). The growth of residential districts in Ibadan. Geographical Review, 56-77.

Milfont, T. L. (2007). Psychology of environmental attitudes: A cross-cultural study of their content and structure. Unpublished doctoral dissertation, University of Auckland, Auckland, New Zealand. http://researchspace.auckland.ac.nz. Curled from the internet on $14^{\text {th }}$ Dec, 2007.

Mohai, P. (1992). Men, women, and the environment: An examination of the gender gap in environmental concern and activism, Society and Natural Resources, 5, pp1-19. Ojedokun, A. O. (2009). Influence of psychosocial factors and mediatory role of environmental attitude on responsible environmental behaviour among residents of high density areas in Ibadan metropolis. An Unpublished PhD Thesis Submitted to the University of Ibadan, Nigeria. 
Ojedokun, A. O, \& Balogun, S. K. (2010).

Environmental attitude as a mediator of the relationship between self-concept, environmental self-Efficacy and responsible environmental behaviour among residents of high density areas in Ibadan metropolis, Nigeria. Ethiopian Journal of Environment Studies and Management, 3, (2), pp 111-119.

Onibokun, A. (1973). Forces Shaping the Psychical Environment of Cities in the Developing Countries: The Ibadan Case. Wisconsin: Wisconsin Press.

Osgood, C. E, Suci, G.J, \& Tannenbaum, P. H. (1957). The Measurement of meaning. Urbana, IL: University of Illinois Press.

Oyo State Government Edict. (1997). Gazette, 22

(8) Ibadan: Ministry of Information, Community Development, Sport and Culture, Ibadan. Place, G, \& Eweret, A. (2001). Impact of the early-life outdoor experiences on an individual's environmental attitude. 2001 Symposium on leisure research, Denver, CO, October 3-6, 2001. Rotter, J.B. (1966). Generalized expectancies for internal versus external control of reinforcement. Psychological Monographs, 80 (whole number, 609).

Samdahl, D. M, \& Robertson, R. (1989). Social determinants of environmental concern:

Specification and test of the model.

Environmental Behaviour, 21, pp 57-81.

Scott, D. (1999). Equal opportunity, unequal results. Environment and Behaviour, 31, pp 267290.
Shamir, B., House, R. J., \& Arthur, M. B. (1993). The motivational effects of charismatic leadership: A self-concept based theory. Organization Science, 4(4), pp 577-594. Stokols, D., \& Altman, I. (Eds.), (1987). Handbook of Environmental Psychology, Vols. 1-2. John Wiley, NY.

Taiwo, A. O, Olapegba, P. O, \& Adejuwon, G. A. (2005). Psychosocial factors associated with smoking behaviour among secondary school adolescents in Ibadan metropolis, African Journal for the Psychological Study of Social Issues, 8 (2), 264-279.

Teisl, M. F, \& O'Brien, K. (2003). Who cares and who acts? Outdoor recreationists exhibit different levels of environmental concern and behaviour, Environmental Behaviour, 29,pp 618-637. The Nation. (2007) \#4.5b Push for Ibadan antifilth battle. October 5, pg. 38 .

Tuttel, D, \& Tuttel, N. (2004). Self-esteem and adjusting with blindness ( $3^{\text {rd }}$ Edition). Springfield, IL. Charles C Thomas.

Van Liere, K. V, \& Dunlap, R. E. (1981). Environmental; concern: Does it make a difference how it's measured. Environment and Behaviour, 13, pp651-676.

Wood, R.E., Bandura, A., \& Bailey, T. (1990). Mechanisms governing organisational performances in complex decision making environments. Organisational Behaviour and Human Decision Processes, 46, pp181-201. Zelezny, L. C., Chua, P., \& Aldrich, C. A. (2000). New ways of thinking about environmentalism: elaborating on gender differences in environmentalism. Journal of Social Issues, 56(3), pp 443-457. 
Table 1: Participants Characteristics

$(\mathrm{n}=1,360)$

\begin{tabular}{|lcc|}
\hline Variable & n & \% of sample \\
\hline Gender & 770 & 56.6 \\
Males & 590 & 43.4 \\
Females & & \\
Marital status & 599 & 44.0 \\
Married & 668 & 49.1 \\
Single & 32 & 2.4 \\
Divorced & 31 & 2.3 \\
Separated & 30 & 2.2 \\
Widowed & & \\
Year of Education & 225 & 16.5 \\
Primary school education & 523 & 38.5 \\
Secondary school education & 222 & 16.4 \\
Teacher training education & 268 & 19.7 \\
Polytechnic/college of education & 88 & 6.5 \\
Bachelor Degree/its equivalent & 34 & 2.5 \\
Postgraduate & & \\
Type of occupation & 333 & 24.5 \\
Government employees & 66 & 4.9 \\
Private organizations' employees & 122 & 9.0 \\
Artisans & 343 & 25.2 \\
Traders & 85 & 6.3 \\
Self-employment & 6 & 0.4 \\
Clergies & 11 & 0.8 \\
Retirees & 357 & 26.3 \\
Students & 37 & 2.7 \\
Unemployed & 250 & 39.4 \\
Residential Status & 672 & 32.2 \\
Landlord & 438 & \\
Tenant & & \\
Staying with parents or a relative & & \\
& & \\
& & \\
\hline
\end{tabular}

Table 2: Correlations among Key Variables of the Study $(\mathbf{n}=1360)$

\begin{tabular}{|l|ccccccc|}
\hline Variables & 1 & 2 & 3 & 4 & 5 & 6 & 7 \\
\hline 1. AL & - & & & & & & \\
2.Altruism & $-.23^{* *}$ & & & & & & \\
3. ESE & $-.21^{* *}$ & $.27^{* *}$ & & & & & \\
4. Self Concept & $-.69^{* *}$ & $.13^{* *}$ & .04 & & & & \\
5. Locus of Control & $.52^{* *}$ & $-.14^{* *}$ & -.08 & $-.56^{* *}$ & - & & \\
6. Age & $-.13^{*}$ & .04 & -.01 & -.05 & -.02 & - & \\
7. Gender & -.03 & .03 & .02 & -.03 & -.03 & -.00 & - \\
$\quad$ Mean & 79.29 & 26.31 & 14.97 & 43.56 & 44.35 & 46.58 & 32.36 \\
SD & 8.53 & 5.32 & 2.90 & 9.17 & 9.80 & 9.15 & 10.98 \\
\hline
\end{tabular}

* Correlation is significant at the 0.05 level, ${ }^{* * *}$ Correlation is significant at the 0.01 level (2-tailed)

Key: $\mathbf{A L}=$ Attitude towards Littering, $\mathbf{E S E}=$ Environmental Self Efficacy 
Table 3: Regression of Attitude Towards Littering on Psycho-socio-cultural Factors

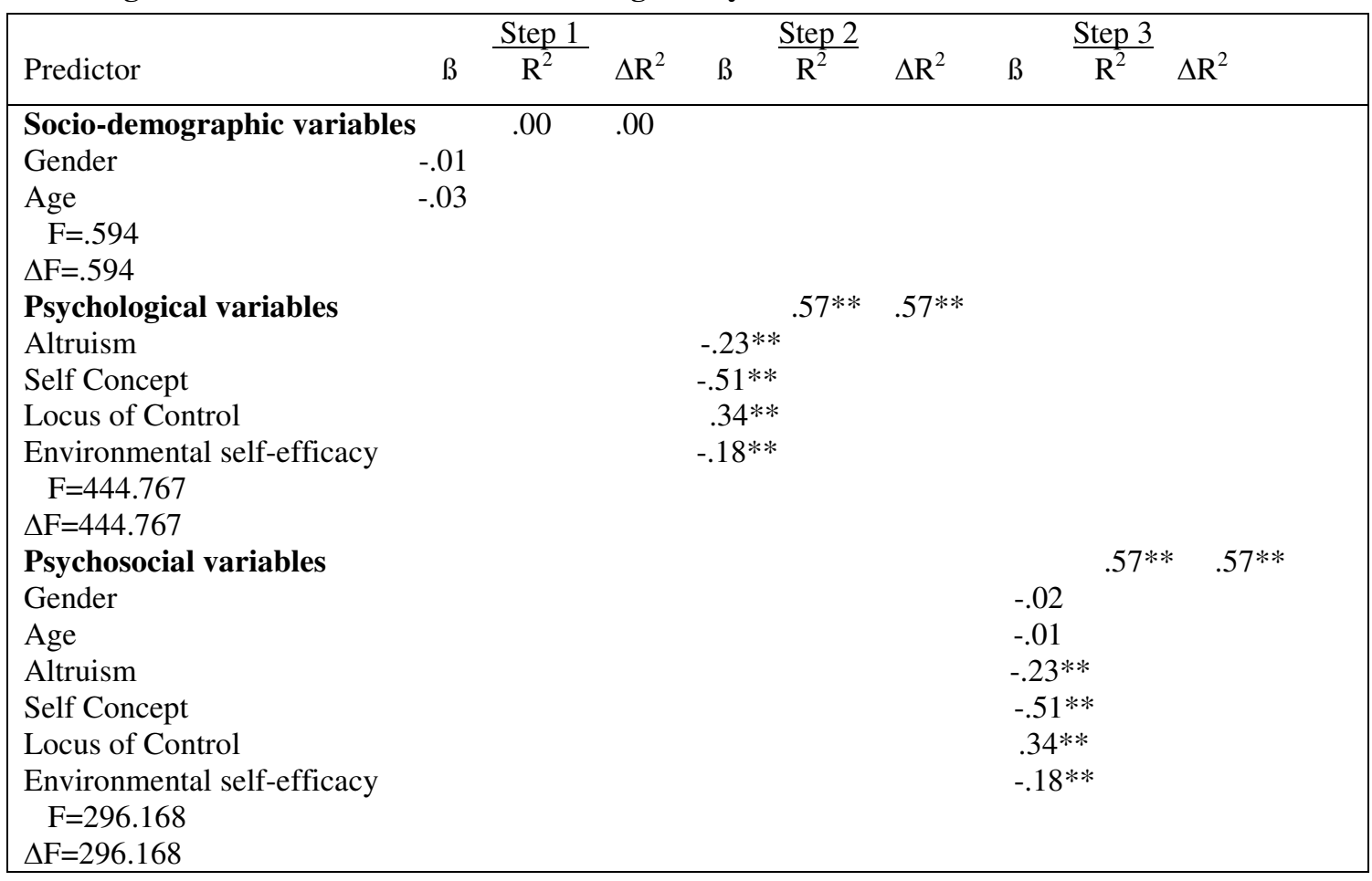

